Research Article

\title{
USG-Guided FNAC of Pediatric Lesions: An Experience and Retrospective Analysis of Two Teaching Hospitals
}

\author{
Devajit Nath', Neema Tiwari $^{2}$, Jyotsna Madan ${ }^{3}, \underline{\text { Savitri Singh }}^{4}, \underline{\text { Parul Gupta }}^{5}$, \\ Nirupma Lal ${ }^{6}$, Sangeeta Tripathy \\ 1,2,3,4 Department of Pathology, SSPH \& PGTI, Sector 30, Noida, U.P., India. \\ ${ }^{5,6}$ Department of Pathology, Eras Lucknow Medical College and hospital, Lucknow, U.P., India. \\ 7Department of Radiology, SSPH \& PGTI, Sector 30, Noida, U.P., India. \\ DOI: https://doi.org/10.24321/2454.8642.201923
}

I $\quad \begin{array}{lllll}\mathbf{N} & \mathbf{F} & \mathbf{O}\end{array}$

\author{
Corresponding Author: \\ Dr. Jyotsna Madan, Department of Pathology, \\ SSPH \& PGTI, Sector 30, Noida, U.P., India. \\ E-mail Id: \\ drjyotsnamadan@yahoo.co.in \\ Orcid Id: \\ https://orcid.org/0000-0003-1951-9438 \\ How to cite this article: \\ Nath D, Tiwari N, Madan J, Singh S, Gupta P, Lal \\ $\mathrm{N}$ et al. USG-Guided FNAC of Pediatric Lesions: \\ An Experience and Retrospective Analysis of \\ Two Teaching Hospitals. Rec Adv Path Lab Med \\ 2019; 5(4): 23-27. \\ Date of Submission: 2019-12-31 \\ Date of Acceptance: 2020-02-27
}

\section{$\begin{array}{llllllll}\mathbf{A} & \mathbf{B} & \mathbf{S} & \mathbf{T} & \mathbf{R} & \mathbf{A} & \mathbf{C} & \mathbf{T}\end{array}$}

Introduction: Accuracy of the FNAC results depends upon the amount and adequacy of the aspirated material from the lesion with proper staining and interpretation. Guided aspirate yields better diagnostic material from deep-seated and inaccessible lesion in comparison to routine FNA procedure.

Aim: To present an experience of 30 cases of USG-guided FNAC in the pediatric population.

Material and Methods: The study is a retrospective data analysis and included 30 pediatric cases of $0-18$ years who were advised image-guided FNAC for various clinical diagnosis. Corresponding slides of the cases were examined from the archives of the Department of Pathology SSPHPGTI, Noida, U.P. and Era's Lucknow Medical University, Lucknow, U.P. India. The variables were tabulated under the headings of demographic data, site of lesion and as per diagnosis as non-neoplastic or neoplastic. Nonneoplastic lesions were further classified into infective, inflammatory/ autoimmune, while neoplastic lesion as benign and malignant tumor. Data was analyzed as per statistical parameter and results were compiled and analyzed.

Result: Out of 30 cases, 16 were females and 14 males with majority of males in the age group of 0 to 10 years and majority of the females in the age group of 11 to 18 years. The most common site to undergo FNAC in our study was abdominal swellings [mesenteric lymph nodes (10) followed by kidney mass (2) and ovarian mass (2)]. Only 3 cases were categorized as malignant lesions, the rest were benign. Infective lesion was the most common category with maximum cases reported as Koch's abdomen (7). Three cases were noncontributory with no adequate yield.

Conclusion: The study is an attempt to highlight our experience of USGguided FNAC diagnosis in pediatric population.

Keywords: USG, FNA, Pediatric, Experience 


\section{Introduction}

Pediatric lesions differ markedly from adult lesions in their nature, distribution, and prognosis. ${ }^{1}$ Pediatric patients represent a unique study population with regard to spectrum and frequency of disease. Fine-Needle Aspiration Cytology (FNAC) is the first choice of investigation for the diagnosis of the palpable lesion or mass. FNAC has also been recommended as a technique for accurate evaluation and diagnosis of childhood palpable lesions. FNA usually is preferred over biopsies because procurement of cytological material from the lesion helps in rapid evaluation and tentative diagnosis, thus helping the clinician and patient in early management of the disease. ${ }^{2-5}$ It has also been shown to be safe, with minimal trauma, and cost-effective diagnostic method that notably typically lacks the need for sedation or general anesthesia in comparison to surgical biopsy. ${ }^{6}$ USG-guided FNAC is a more refined form of this technique used especially in deep-seated lesions or lesions near major vessels, which cannot be approached blindly. The benefit of image guidance is that we get a better understanding of the location of the lesion, the needle goes in the lesion so chances of dilution of material by blood is reduced drastically and we get a better yield on the slides examined; hence, a better and faster diagnosis can be done.

Our study aims at presenting a 2-year experience of our pediatric setup to highlight the spectrum of diseases on USG-guided FNAC.

\section{Materials and Methods}

A retrospective descriptive case study for 2 year data was conducted and included 30 pediatric cases of 0 to 18 years who were advised image-guided FNAC for various clinical diagnosis. Corresponding slides of the cases were examined from the archives of the Department of pathology SSPHPGTI, Noida and Eras Lucknow medical University, Lucknow. Since it is a retrospective data analysis prior ethical approval was not required. All pediatric cases who had undergone routine USG guided FNACs were included in the study and all adult cases or any guided smear of a known case on treatment were excluded. A Lumbar Puncture (LP) needle was used for the procedure and smears were air dried as well as wet fixed. All smears were stained with Romanowsky stains (Leishman). Papanicolaou stain along with Periodic Acid and Schiffs stain, Ziehl-Neelsen stain for acid fast bacilli and Gram stain for gram positive/negative bacteria were done as and when required.

The data was tabulated under the headings of demographic data, site of lesion and diagnosis as non-neoplastic and neoplastic diseases. Non-neoplastic lesions were further classified into infective, inflammatory/ autoimmune, while neoplastic lesion were classified as benign and malignant. Analysis of the data was done and results presented.

\section{Result}

Out of 30 cases, 16 were females and 14 males with majority of males in the age group of 0 to 10 years and majority females in the age group of 11 to 18 years. The most common site to undergo FNAC in our experience was abdominal swellings [mesenteric lymph nodes (10) followed by kidney mass (2) and ovarian mass (2)]. Only 3 cases were categorized as neoplastic, malignant lesions, the rest were non-neoplastic. Infection was the most common non-neoplastic category with maximum cases reported as Koch'sabdomen (7) (Figure 1 (A-E) and Table 1-4). Three cases were noncontributory with no adequate yield.

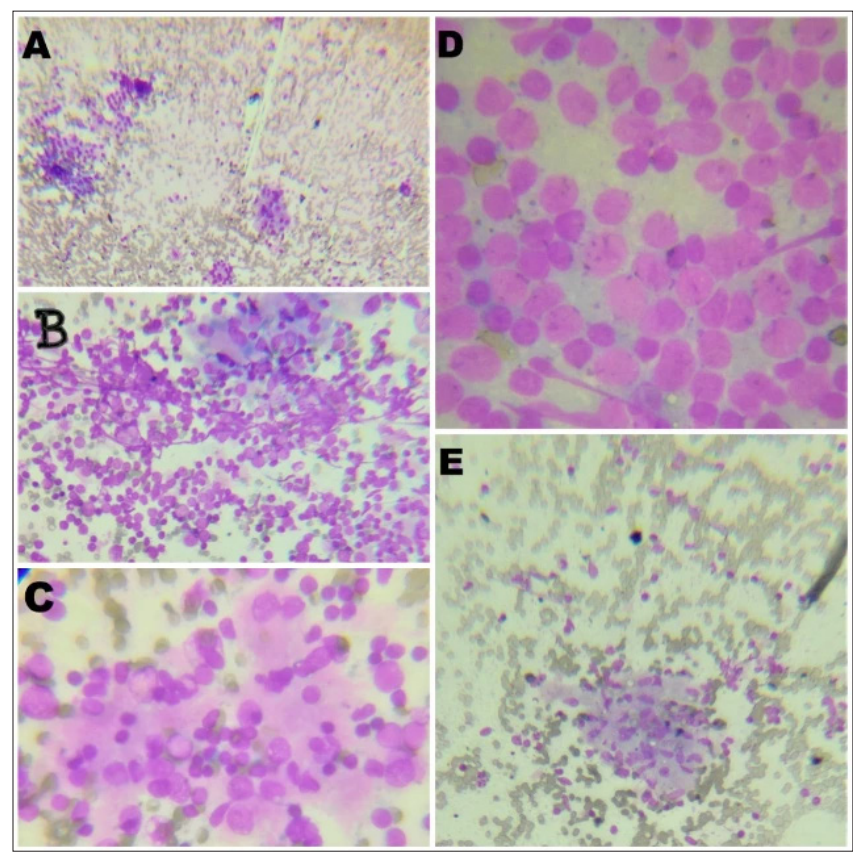

Figure I.A, B, C Moderately cellular smear with aggregates of oncocytes and mature lymphocytes; also follicular cells and plasma cells suggestive of lymphocytic thyroiditis (USG-guided aspirate from thyroid, Giemsa stain). D Monomorphous population of medium sized lymphoid cell suggestive of atypical lymphoid proliferation (USG-guided aspirate from abdominal lymphnode, Giemsa stain). E Well-defined epithelioid cell granuloma suggestive of granulomatous inflammation (USG-guided aspirate from abdominal lymph node Giemsa stain)

Table I.Demographic data of the study population

\begin{tabular}{|c|c|c|}
\hline Age (Years) & Male & Female \\
\hline $0-10$ & 10 & 04 \\
\hline $11-18$ & 04 & 12 \\
\hline
\end{tabular}

Table 2.Sex distribution of cases

\begin{tabular}{|c|c|}
\hline Males & Females \\
\hline 14 & 16 \\
\hline
\end{tabular}


Table 3.Site of USG-guided FNAC (Organs involved)

\begin{tabular}{|c|c|c|c|}
\hline S. No. & Site & Male & Female \\
\hline 1. & Kidney & 02 & 00 \\
\hline 2. & Cervical lymphnode & 03 & 02 \\
\hline 3. & Abdominal lymphnode & 06 & 04 \\
\hline 4. & Thyroid & 00 & 02 \\
\hline 5. & Soft Tissue Swelling (STS) & 02 & 02 \\
\hline 6. & Ovary & 00 & 02 \\
\hline 7. & Axillary swelling & 00 & 01 \\
\hline 8. & Pleural cavity & 01 & 00 \\
\hline 9. & Non contributory & 02 & 01 \\
\hline
\end{tabular}

Table 4.Cytomorphological diagnosis of the lesion

\begin{tabular}{|c|c|c|c|c|c|c|c|c|}
\hline \multicolumn{4}{|c|}{ Non Neoplastic (18) } & \multicolumn{4}{|c|}{ Neoplastic (09) } & \multirow{3}{*}{$\begin{array}{c}\begin{array}{c}\text { Non } \\
\text { Contributory }\end{array} \\
03\end{array}$} \\
\hline \multicolumn{2}{|c|}{ Infective } & \multicolumn{2}{|c|}{ Inflammation/ autoimmune } & \multicolumn{2}{|l|}{ Benign } & \multicolumn{2}{|l|}{ Malignant } & \\
\hline Parasite & 02 & Hashimoto's thyroiditis & 02 & Vascular & 02 & Lymphoma & 01 & \\
\hline Suppurative & 07 & & & Mucinous cyst ovary & 01 & *SRBCT & 01 & \\
\hline \multirow[t]{2}{*}{ TB } & 07 & & & Benign ovarian cyst & 01 & Wilms Tumor & 01 & \\
\hline & & & & lipoma & 02 & & & \\
\hline
\end{tabular}

*SRBCT-Small round blue cell tumor

\section{Discussion}

Pediatric patients represent a unique study population with regard to spectrum and frequency of disease. Fine-Needle Aspiration Cytology (FNAC) is the first choice of investigation for the diagnosis of the palpable lesion or mass however not many studies are available compiling pediatric data for USG guided FNACs.

A thorough literature review showed only 1 report analyzing all FNAs, both benign and malignant, performed at a large medical center in children 12 years of age and younger. ${ }^{7}$ The role of FNA in children has been described in numerous studies. ${ }^{8-9}$ According to a study done on guided FNACs of retroperitoneal lesions in pediatric population the sensitivity, specificity and diagnostic accuracy of FNACs was $92.8 \%, 100 \%$ and $93.3 \%$, respectively. ${ }^{8}$ Previous publications have focused on FNA of specific anatomic sites or of particular disease entities. Another study done outside India is based on a 10-year experience of pediatric FNACs. However, to the best of our knowledge this is the first study to be highlighting the findings as well as the importance of guided FNACs in the pediatric population. ${ }^{9}$

There is very limited data defining the application of imageguided FNA cytology to lesions of multiple anatomic sites in the pediatric population. In a study of guided FNAC in mixed pediatric and adult population, majority cases were that of thyroid lesions while in our study, lymph nodes appear to be the commonest organ to be sampled in the pediatric population. ${ }^{10}$

The commonly detected non-neoplastic lesions in our study were infective with equal number of tubercular and bacterial lesions. Rest all other lesions were in almost similar frequency. Only 3 malignant cases were diagnosed. The patients were classified in two age groups: 0 to 10 and 11 to 18 years. It was interesting to see male preponderance in the 0 to 10 years age group and female preponderance in 11 to 18 years age group. In a study in regard to gender, the mean age of lesion in male was lower than that of female patients $(10.81 \pm 5.60$ years vs. $14.56 \pm 4.37$ years) thus matching our study. ${ }^{11}$

Study shows that the most common cancer in children aged 0 to 14 are acute lymphocytic leukemia, central nervous system tumour, neuroblastoma, and non-Hodgkin lymphoma and the most common cancers among adolescents aged 15 to 19 years are Hodgkin lymphoma, thyroid carcinoma, and lymphoma. ${ }^{11-13}$

In another study from guided retroperitoneal lesions on mixed population with larger sample size, 31 malignant lesions and 16 benign and inflammatory lesions were described. In this study, out of 23 renal masses, 11 cases were Wilms Tumor, 4 cases were Renal cell carcinoma and a single case constituted angiomyolipoma of kidney. There were 20 cases of retroperitoneal lymphadenopathy with 
12 cases (60\%) as inflammatory mainly tuberculosis and 8 cases (40\%) had malignancy. There were 7 miscellaneous retroperitoneal masses out of which 3 were fibrohistiocytic tumor, 2 were myxoid liposarcoma, 1 was neuroblastoma and 1 was seminoma. ${ }^{11}$

Tuberculosis is a very common entity to be diagnosed in Indian population and in our study mostly the children were diagnosed with TB and majority had a positive family history or a recent exposure history to tuberculosis. Two cases of thyroiditis were diagnosed while benign lesions were vascular and lipoma followed by ovarian cysts. Small Round Blue Cell Tumor (SRBCT) was the common diagnosis on USG-guided FNA from retroperitoneal lesion with one being confirmed on histopathology as lymphoma and the other as Wilms tumor. One case was lost to follow up.

In our study, the majority of lesions were non-neoplastic which matches the findings of another study. ${ }^{12,13}$ Only 3 malignant cases were identified in our study. In general, examination of smear for malignancy may pose a problem due to presence of features like hypocellularity, degenerated tumor cells, necrosis, and epithelial hyperplasia. The falsenegative cases in FNAC are commonly due to poor tumor localization and poor sampling technique. A small sample size was one limitation in our study.

\section{Conclusion}

In conclusion, our study supports the use of guided FNAC in deep-seated lesions of various anatomic sites in the children less than 18 years old. It is a simple and minimally invasive tool in rapid evaluation and early diagnosis for better and timely management of deep-seated and unapproachable lesions.

\section{Acknowledgement}

Monika Singh, Mayank Mani Pandey, Technical Staff, Dept. of Pathology, SSPHPGTI, Noida, U.P.

\section{Conflict of Interest: None}

\section{References}

1. Yang SI, Park KK, Kim JH. Thyroid metastasis from breast carcinoma accompanied by papillary thyroid carcinoma. Case Rep Oncol 2014; 7(2): 528-533. Available from: https://www.karger.com/Article/Abstract/365748 [DOI: 10.1159/000365748/ PubMed/ Google Scholar].

2. Wang JT, Huang R, Kuang AR. Comparison of presentation and clinical outcome between children and young adults with differentiated thyroid cancer. Asian Pac J Cancer Prev 2014; 15(17): 72717275. Available from: http://journal.waocp.org/ article_29758_8903cad720fdd3ce1dd7e0d696c38fd8. pdf [DOI: 10.7314/APJCP.2014.15.17.7271/ PubMed/ Google Scholar].
3. Chindris AM, DiehI NN, Crook JE, Fatourechi V, Smallridge RC. Undetectable sensitive serum thyroglobulin $(<0.1 \mathrm{ng} / \mathrm{ml})$ in 163 patients with follicular cell-derived thyroid cancer: results of rhTSH stimulation and neck ultrasonography and long-term biochemical and clinical follow-up. J Clin Endocrinol Metab 2012; 97(8): 27142723. Available from: https://academic.oup.com/jcem/ article/97/8/2714/2823315 [DOI: 10.1210/jc.20113017/ PubMed/ Google Scholar].

4. Cappelli C, Pirola I, De Martino E, Gandossi E, Cimino E, Samoni F et al. Thyroglobulin measurement in fine-needle aspiration biopsy of metastatic lymph nodes after rhTSH stimulation. Head Neck 2013; 35(1): E21-E23. Available from: https://onlinelibrary.wiley. com/doi/abs/10.1002/hed.21796 [DOI: 10.1002/ hed.21796/ PubMed/ Google Scholar].

5. Uruno T, Miyauchi A, Shimizu K, Tomoda C, Takamura Y, Ito $Y$ et al. Usefulness of thyoglobulin measurement in fine-needle aspiration biopsy specimens for diagnosing cervical lymph node metastasis in patients with papillary thyroid cancer. World J Surg 2005; 29(4): 483-485. Available from: https://link.springer.com/ article/10.1007\%2Fs00268-004-7701-0 [DOI: 10.1007/ s00268-004-7701-0/ PubMed/ Google Scholar].

6. Cunha N, Rodrigues F, Curado F, Ilhéu O, Cruz C, Naidenov $P$ et al. Thyroglobulin detection in fine-needle aspirates of cervical lymph nodes: a technique for the diagnosis of metastatic differentiated thyroid cancer. Eur J Endocrinol 2007; 157(1): 101-107. Available from: https://eje.bioscientifica.com/view/journals/ eje/157/1/1570101.xml [DOI: 10.1530/ EJE-07-0088/ PubMed/ Google Scholar].

7. Giovanella L, Ceriani L, Suriano S. Lymph node thyroglobulin measurement in diagnosis of neck metastases of differentiated thyroid carcinoma. J Thyroid Res 2011; 2011: 621839. Available from: https:// www.hindawi.com/journals/jtr/2011/621839/ [DOI: 10.4061/2011/621839/ PubMed/ Google Scholar].

8. Agrawal P, Gupta A. Role of image Guided Fine Needle Aspiration Cytology in Diagnosis of Retroperitoneal Lesions in Pediatric Population. Journal of Evolution of Medical and Dental Sciences 2014; 3(72): 15290 15296. Available from: https://pdfs.semanticscholar. org/1dcd/d8509afdbb80e7191751d33afefc2fd34c95. pdf [DOI: 10.14260/jemds/2014/4057/ ResearchGate/ Google Scholar].

9. Sohn YM, Kim MJ, Kim EK, Kwak JY. Diagnostic performance of thyroglobulin value in indeterminate range in fine needle aspiration washout fluid from lymph nodes of thyroid cancer. Yonsei Med J 2012; 53(1): 126-131. Available from: https://synapse. koreamed.org/search.php?where=aview\&id=10.3349/ ymj.2012.53.1.126\& code=0069YMJ\&vmode $=F U L L$ 
[DOI: 10.3349/ymj.2012.53.1.126/ PubMed/ Google Scholar].

10. Mangla G, Arora VK, Singh N. Clinical audit of ultrasound guided fine needle aspiration in a general cytopathology service. J Cytol 2015; 32(1): 6-11. Available from: http:// www.jcytol.org/article.asp?issn=0970-9371; year $=201$ 5 ; volume $=32$;issue $=1 ;$ spage $=6$; epage $=11$; aulast $=$ Man gla [PubMed/ Google Scholar].

11. Szakáll S Jr, Esik O, Bajzik G, Repa I, Dabasi G, Sinkovics I, et al. 18F-FDG PET detection of lymph node metastases in medullary thyroid carcinoma. J Nucl Med 2002; 43(1): 66-71. Available from: http://jnm.snmjournals. org/content/43/1/66.long [PubMed/ Google Scholar].

12. Salvatore $B$, Paone $G$, Klain $M$, Storto $G$, Nicolai $E, D$ 'Amico $D$, et al. Fluorodeoxyglucose PET/CT in patients with differentiated thyroid cancer and elevated thyroglobulin after total thyroidectomy and (131) I ablation. Q J Nucl Med Mol Imaging 2008; 52(1): 2-8. Available from: https://s3.amazonaws.com/academia. edu.documents/45342047/Fluorodeoxyglucose_ PETCT_in_patients_wit20160504-30608-k8z2qv. pdf?response-content-disposition=inline $\% 3 \mathrm{~B} \% 20$ filename\%3DFluorodeoxyglucose_PET_CT_in_ patients_wi.pdf\&X-Amz-Algorithm=AWS4-HMACSHA256\&X-Amz-Credential=AKIAIWOWYYGZ2Y53 UL3A\%2F20200304\%2Fus-east-1\%2Fs3\%2Faws4_ request\&X-Amz-Date $=202003041102659 Z \& X-A m z-$ Expires $=3600 \& X-A m z-S i g n e d H e a d e r s=h o s t \& X-A m z-S i$ gnature $=9 e 260 f 6375 d 8 b 9963 f 692 c 62 a c 2 a 20 b 4 c 16 c 3$ 4cbde11ac09b8c74d718e786dd1 [PubMed/ Google Scholar].

13. Li L, Chen BD, Zhu HF, Wu S, Wei D, Zhang JQ, et al. Comparison of Pre-operation Diagnosis of Thyroid Cancer with Fine Needle Aspiration and Coreneedle Biopsy: a Meta-analtsis. Asian Pac J Cancer Prev 2014; 15(17): 7187-7193. Available from: https://pdfs.semanticscholar.org/9347/e9d523f7c b98b141217b7708187b3813e11d.pdf [DOI: 10.7314/ APJCP.2014.15.17.7187/ PubMed/ Google Scholar]. 